\title{
Omni Channel Health:
}

Envisioning Sarāh's Retail

Consumer Experience

in Healthcare

\section{Praveen Chopra}

$4 / P$ 
$t$ is a beautiful Friday morning and a great start to the spring in Philadelphia as the trees begin to flower and the birds chirp happily. Sarah, a retail professional, is getting ready for her spring vacation with her husband, Mohan, and 10-year-old son, Jacob. They have been looking forward to this vacation for a few years, since Jacob was diagnosed with asthma and seasonal allergies. 
Sarah is working through her last-minute checklist before they fly out tomorrow to Florida. As she packs her swimsuit, she notices a small rash on her left arm. "I will get it checked when I come back," she murmurs to herself, and continues packing.

Then she vaguely remembers receiving an e-mail from her employers about the launch of a new telehealth program. The e-mail said something about being able to see a doctor any time and from anywhere. She grabs her iPhone and searches for "teleheath." The e-mail pops up and she starts scrolling down ... "easy app download...virtual visit with a physician...no fee." She's not sure exactly how it will work but decides to give it a try. She clicks on the quick registration button from the e-mail to download and register the app on her iPhone. "Wow," she thinks to herself, "if the first step was that easy, I should try this for my rash." Within the app she scrolls through the physician listing and is thrilled to see the name of her primary care physician. All of a sudden, after clicking the name to initiate the telehealth session, Dr. Goldberg's face pops up and she hears "Hello, Sarah!"

Sarah went on to share information about her rash and asked if she needs to cancel her vacation. Dr. Goldberg asks to see the rash, and after examining through the iPhone, gives her the green light to proceed with her vacation. Before signing off, Dr. Goldberg asks to see a picture of the rash using secure messaging on the patient portal. "An iPhone picture is fine." Lastly, he asks for the nearest pharmacy to her house so he can send a prescription for a rash cream that she can pick up on her way to the airport.

What is Telehealth?

Not just a video talk. Any

electronic communication

between clinicians and pa-

tients that may include data

feeds, asynchronous and

synchronous exchanges, as

well as video conversations.

After $\mathbf{2 0}$ years of slow adop-

tion, 2014 is seen as the begin-

ning of widespread adoption,

with an estimated 75 million

telehealth visits in the United

States (DeLoitte: "eVisits, the

21st century housecall").

Sarah takes a deep breath of relief as she sits back down on the couch and realizes what just happened. In less than 15 minutes, the physician was available through her smartphone, her packing was essentially uninterrupted as she was in her pajamas, and she didn't have to leave the house! She continues packing while humming to her favorite music, only to be interrupted by a text notification from her pharmacy that her prescription is ready for pick-up. She chuckles and carries on...

The next day after reaching their seaside hotel, Sarah, Mohan, and Jacob go for a leisurely walk on the beach followed by a relaxing dinner. Just minutes after lights out, Sarah and Mohan wake up to a loud wheezing noise. They run to Jacob's room to find him gasping for air. It is not the first time Jacob has been through this, but it has been a while since he had a similar episode. Sarah and Mohan know what to do. They rush Jacob to the nearest emergency department. The attending, Dr. Salinas, first asks if Jacob is on any medications and if he has any 


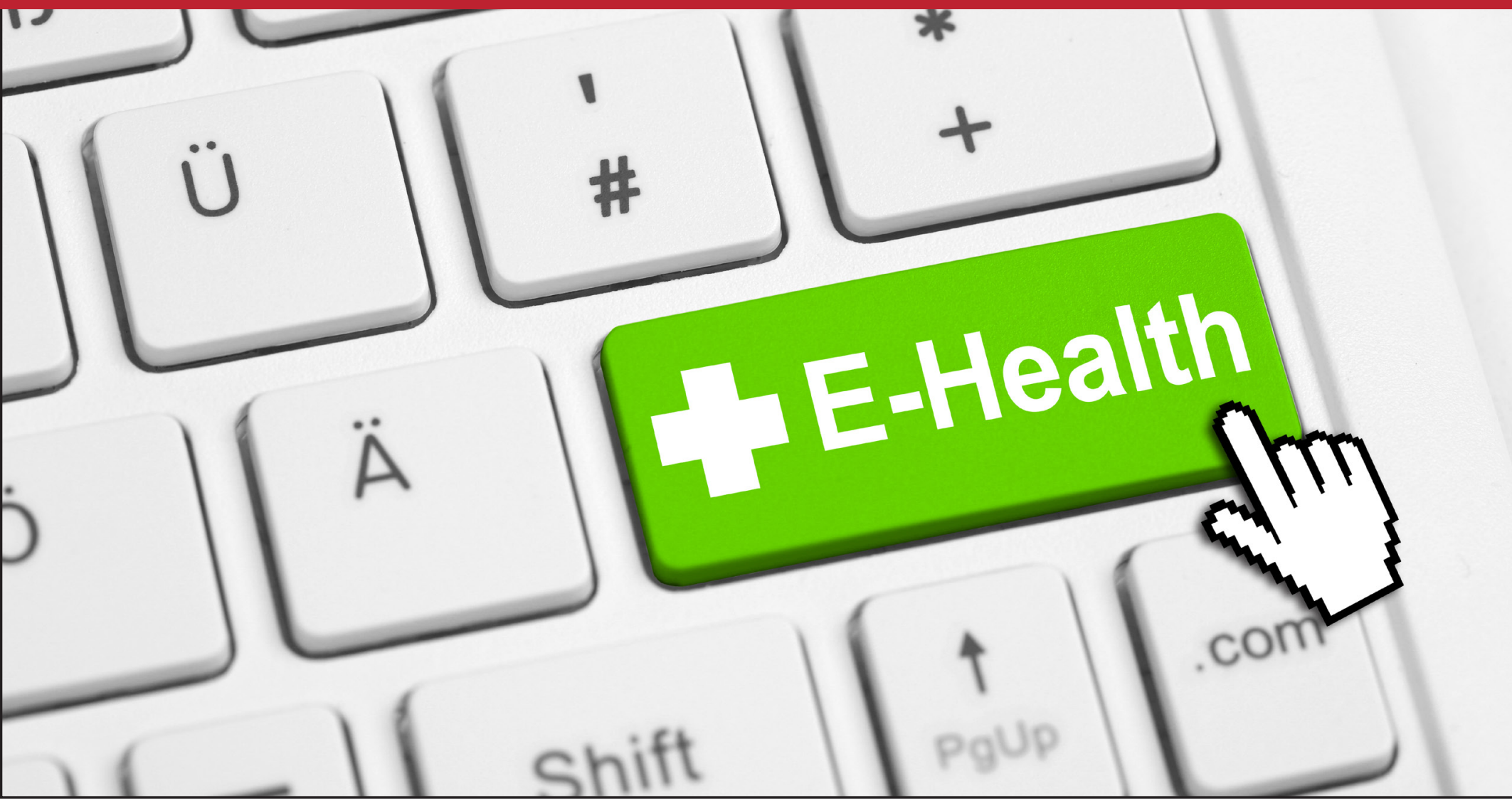

related allergies. While she doesn't have the information handy, Sarah knows that information is catalogued within Jacob's virtual medical home in Philadelphia. Dr. Salinas' eyes light up, and he asks for the medical home name and location. Next thing they know, the attending uploads Jacob's medical information from Philadelphia directly into the local system where Dr. Salinas is able to access it immediately. He administers the proper medication and within 3 hours of arriving at the emergency room, Mohan and Sarah are back at the hotel putting Jacob to bed.

After what is a much more peaceful night's rest, Jacob wakes up just as playful and active as if the incident at night never happened. Mohan and Sarah are relieved and energized by the seamless, convenient, and hassle-free experience they just encountered. They are grateful that through new technology, Dr. Salinas was able to access the right information at the right time. Just as they are walking out the door, Jacob's pediatrician, Dr. Elizabeth Carr, calls from Philadelphia to let them know that she received an encounter notification about Jacob's emergency visit and that she has debriefed the encounter with Dr. Salinas at the Florida hospital. Everyone is effectively and efficiently on the same page and there is no need to worry. Dr. Carr asks Sarah to bring Jacob for a check-up when they return from Florida.

Mohan, Sarah, and Jacob enjoy the rest of their day on the beach. Later that night, Sarah logs into her patient portal to schedule an appointment for Jacob. At the top of the screen she sees a new notification. She clicks on the button and is pleased to

More than 1,800 retail clinics have 10.5 million visits annually.

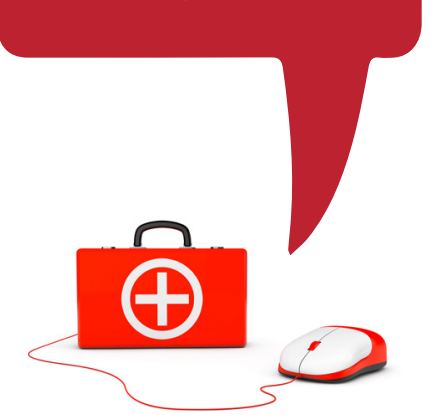


learn there is an ambulatory care center near her house where she can get an appointment for Jacob. She also notices her primary care physician has office hours in the same location. Since the rash is still on her mind, she schedules office visits for both Jacob and herself on the same day and location upon their return from Florida.

The next 5 days are a breeze. It has been a long time since they have been able to relax as a family, and after a rocky start, it only gets better.

They return to Philadelphia refreshed and energized. Sarah visits the doctors at the ambulatory care center the next week and returns with a clean bill of health for both Jacob and herself. Dr. Carr also prescribes a wi-fi-enabled inhaler for Jacob that is synchronized to an asthma app on Sarah's iWatch. The app monitors pollution and pollen levels to provide a proactive health monitor for Jacob at Sarah's fingertips, or should we say her wrist.

Mohan smiles and takes Sarah's hand. They can hear Jacob waking up from his nap. They look at each other, smile, and walk into the house. 


\section{Response: Ninfa Saunders, DHA}

\section{This story captures a human journey in a large transformation of healthcare toward what we call retail medicine.}

The following weekend Sarah and Mohan were sitting on their patio enjoying the spring scenery while Jacob was taking a nap. Sarah looks at Mohan and exclaims, "Aha ... welcome to retailization of healthcare. Over the last few weeks, we just saw healthcare at its finest-a consumer-centric retail experience where the location or channel no longer dictate how you receive care. Instead, you have the care coming to you, just as a product we order arrives when we need it. I can relate! Omni Channel Health is here to stay, and it makes me feel safe and secure. I love this new way of living."

Our world is full of Sarahs, Mohans, and Jacobs. They are taking charge, navigating healthcare systems on their own, and directing their care. They know they have options and the right to choose, and they will make that choice!

But this human story raises the key question for us: How do we as providers, insurers, and guides help this economic trend become a win-win for our patients? I believe it can be done.

The Institute For HealthCARE Improvement's (IHI) framework for optimizing healthcare and patient experience revolves around right access to the right care at the right time. At the same time that we are pursuing the IHI's framework, we're experiencing the compendium elements of payment reform, insurance reform, delivery of care reform, consumerism, and price transparency. The result: the accelerated emergence of alternative care delivery systems, in particular, the "retailization" of healthcare. Kaufman Hall defines retail care as a consumer-driven approach to care delivery that is grounded in retail principles and compelled by market forces that empower and incentivize patients to become consumers of healthcare and well care services.

This phenomenon is driven by factors that include:

- higher out-of-pocket costs for insured patients

- transparency of price and quality data (or perceived quality) leading to actionable consumer information

- new and competitive entrants to the industry

- consumer expectations related to convenience and service

- new technology, high connectivity, and virtual one-click apps

Consumer choice has become a growing determinant of care access and utilization, and alternative care models have emerged and have grown exponentially, primarily outside the confines of traditional healthcare delivery systems. Harvard professor Michael E. Porter's Five Forces of Rivalry in a Competitive Market has found its place in the healthcare industry where new entrants and threats of substitution have become a stark reality.
$58.6 \%$ of U.S.

families who have

used a retail clinic

in the past year

said they used it

because the hours

were more

convenient than

a traditional

healthcare facility. 
"no longer our father's economy." Contemplate we should and act we must if we plan to compete in this marketplace and ensure that the outcomes of disruption are good for our patients.

Ninfa M. Saunders

President and CEO, Navicent Health

Cofounder, Stratus Healthcare

Email: saunders.ninfa@navicenthealth.org

\section{Healthcare Without Walls: Platforms of the Future}

1. Mobile health (mHealth) and telehealth become a starting point for health and healthcare. Together, retail medicine and telehealth take over large segments of primary care.

2. Internet of things (IoT) becomes a fabric connecting various devices to exchange data.

3. Healthcare will enter the "one-tap economy." Consumers will choose e-prescriptions at retail pharmacies, online management of appointments, and personal control over electronic health records redesigned for users.

4. Artificial intelligence generates customized and actionable health alerts for habit change and lifestyle guidance.

5. Neighborhood-based healthcare becomes common via pharmacies, grocery stores, emerging health professions, and new patterns of clinician deployment.

6. The shift of primary care to neighborhoods will create opportunities to reduce issues of racial disparities and economic access. 